\title{
Mapping gender differences in understanding about HIV/AIDS
}

\author{
Surjit Singh, Gauhar Raza, S.N. Misra, Pushpa Dahiya
}

\begin{abstract}
The present article investigates public understanding of HIV/AIDS related issues that touch the thought structure of common citizen, among the Indian public. Analysis is based on a representative sample collected from 10 states of India. The authors have also analysed the relative cultural distance at which men and women, as separate groups, could be placed. The relative cultural distance, for each of the selected issues, has been computed and it was found that men, as a group, are closer to scientific thought structure compared to women.
\end{abstract}

\section{Introduction}

The establishment of research area as public understanding of science, a few decades ago, led to random sample survey studies in many countries ${ }^{1,2}$. The increase in government and academic interest in knowing the people's knowledge about science and scientific discoveries (collectively called public understanding of science) stimulated in establishment of centres for research in this area ${ }^{3}$. In many parts of the world, like USA, Britain and European Union, these studies are conducted on regular intervals ${ }^{4}$. The results of the studies in Britain and USA revealed that public interest in science, technology and medicine is relatively higher but their knowledge in each area is comparatively low. The results indicated that though largely publics in these countries are uninformed, their level of interest in science is very high ${ }^{5}$.

During the early phase of the development of the research area, mostly survey studies were conducted to probe the opinion, attitude, literacy, perception and understanding of the public about science, technology, engineering and their perceptions about the community of scientists ${ }^{6}$. Miller conducted survey studies on US population and explained three components of scientific literacy, in terms of knowing about norms of science, knowledge of major scientific constructs and awareness of the impact of science and technology on society ${ }^{78}$. Einsiedel, who conducted empirical studies among Canadian adults concluded that education and gender are best predictors for literacy and in turn literacy relates to trustattitude and efficacy9. With the development of research area, more varied research is being conducted in recent years using various statistical tools for analysis of data ${ }^{10}$ or more towards theoretical aspects, such as cognitive dimension of public understanding of science ${ }^{11}$. Research carried out in various countries has contributed with different aspects, which led to the development of Deficit model ${ }^{12}$ or cultural model ${ }^{13}$ of public understanding of science.

Social scientists and researchers, during recent years, have diverted their attention to this new research field all over the globe and started contributing and comparing the research results of various countries. US public were found better informed about laser and antibiotics while Japanese public had higher level of knowledge about Big Bang and human evolution. The level of information in the two countries is equal in the areas of atomic science, earth science and continental drift ${ }^{14}$. For the purpose of comparing and contrasting the results, researchers conducted surveys among people using the already available questionnaires ${ }^{15}$.

Results of these survey studies in different countries have revealed that in some countries, in general, the public attitude towards science and scientists is found to be favourable, while some observers have found low level of knowledge and poor attitudes towards scientific developments ${ }^{16}$.

There has been tremendous growth in literature on public understanding, attitude and knowledge towards science, technology and scientific developments, and in addition researchers have also generated 
data on specialized fields of science such as biotechnology ${ }^{17,18}$, animal science ${ }^{19}$, environmental science. $^{20}$

The research on the effects of gender has received lesser attention. In recent years, some research work has been carried out comparing the attitude and knowledge according to the gender ${ }^{212223}$. There has been a general comment by research analysts that women have little interest in or knowledge of scientific matters compared to men folk, irrespective to countries. Researchers attribute this low level of understanding to lower educational level among women (science education in particular), religious belief and their nature of work ${ }^{24}$

Recent researches in the area of public understanding of science recommends that this assumption may not be true for all sciences and there are empirical research results which show that women fared better than the men in understanding the area of health and hygiene ${ }^{25}$. The reason for better understanding, it is argued, is that onus of upbringing children in the family lies with the women folk. The results of the study carried out by Bernadette and Vicki also suggests that the matters that directly involve the familial and domestic concern of women such as, potential medical benefits of recent scientific discoveries are better understood by female ${ }^{26}$.

\section{Towards understanding of HIV/AIDS}

Since the identification of the first case in 1981 in USA, AIDS has taken a great toll of human lives all over the world. In order to control its spread and save lives, researchers have engaged in many scientific disciplines such as epidemiology ${ }^{27}$, vaccine development ${ }^{28}$, antiretroviral therapy ${ }^{29}$, etc., but very few studies have been carried out on understanding of HIV/AIDS related issues among the publics ${ }^{30}$. In 2004, a study on perception of adolescent girls was conducted in India ${ }^{31}$. The study focused on general information, perceptions about difference in HIV and AIDS, risk factors, modes of spread of HIV/AIDS, knowledge about AIDS, and attitude towards AIDS. The report also presented a comparative analysis of data collected in India and a similar survey study conducted on students in Ontario (Canada). ${ }^{32}$ The analysis revealed that in both data sets response pattern were quite similar and identical misconceptions were prevalent among the adolescent populations.

During earlier years of the spread of HIV/AIDS, it was difficult to carry out attitudinal studies. However, a study conducted in 1989, in India, showed that since AIDS is a life threatening disease, the information about it had reached even the remote corners of the country. A substantial percentage of illiterate population had included it in their list of five most prevalent diseases, which they could identify by name $\mathrm{e}^{33}$.

Almost all the empirical studies show that general level of information about health issues is relatively high among women when compared with men. Contrary to the earlier findings, a national survey study conducted in India, in 2003, showed that women scored low on questions related to HIV/AIDS compared to men. More than 35000 respondents were surveyed from about 24 states of India on issues about general information, transmission, prevention and cure, detection and tests, STIs and HIV infection, attitude towards disease and patient, and peoples' participation in awareness programmes ${ }^{34}$.

\section{Present study}

Subsequently, a survey was conducted in 10 states of the country, chosen for implementation of the UNAIDS programme; 'Prevention of Trafficking and AIDS among women and children' known as TAHA Project. An open-ended questionnaire was developed for carrying out survey. Special training sessions were conducted for the Nehru Yuva Kendra Sangathan ${ }^{35}$ (NYKS) volunteers on methodology of carrying out the scheduled interviews among the respondents. During the survey operation, structured questionnaire was used to interview more than 12,000 respondents. Specific questions for probing understanding, attitude and perception about various aspects of AIDS were included in the schedule.

The aim of the data analysis was to map the cultural distance ${ }^{36}$ at which men and women could be placed. The authors, in the following paragraphs, on the basis of comparative cultural distance, have tried to analyse gender biases related to issues of HIV/AIDS that exist in the awareness level of the two segments. 


\begin{tabular}{|l|l|l|l|}
\hline \multicolumn{1}{|c|}{ Age } & Percent & Education & Percent \\
\hline $16-20$ yrs & 8.9 & Illiterate & 8.8 \\
\hline $21-25$ yrs & 19.5 & Pre-Primary & 3.2 \\
\hline $26-30$ yrs & 20.7 & Primary & 15.5 \\
\hline $31-35$ yrs & 15.9 & Middle & 8.7 \\
\hline $36-40$ yrs & 15.2 & Secondary & 25.6 \\
\hline $41-45$ yrs & 8.9 & Sr Secondary & 17.5 \\
\hline $46-50$ yrs & 6.3 & Graduate & 14.9 \\
\hline Above 50 yrs & 4.4 & Postgraduate & 2.7 \\
\hline
\end{tabular}

Table 1a. Age-wise and Education-wise distribution of sampled population.

Table 1a provides information about the characteristics of population according to the age and education. Age was divided into eight age groups with 5 years range. All respondents 'above 50 years' were clubbed together. About 80 percent of the sampled population was below 41 years with highest percentage $(20.7$ percent) in the age group 26-30 years. Education-wise distribution showed that 8.8 percent did not go through formal system of education and highest percentage of respondents was at secondary level (25.6 percent). 14.9 percent of the respondents were graduates and 2.7 percent were post-graduates.

\begin{tabular}{|l|l|l|l|}
\hline Occupation & Percent & Gender & Percent \\
\hline not mentioned & .9 & Male & 68.6 \\
\hline Unskilled worker & 10.4 & Female & 31.4 \\
\hline Skilled worker & 9.1 & & \\
\hline Govt. service & 4.9 & & \\
\cline { 1 - 2 } Private service & 7.3 & \\
\cline { 1 - 2 } Student & 7.7 & \\
\hline Business & 5.8 & \\
\hline Household work & 16.5 & \\
\hline Professional & 1.0 & \\
\hline Petty-trader & 2.8 & \\
\hline Agriculture & 23.5 & \\
\hline Driver & 1.2 & \\
\hline Coolie & 3.0 &
\end{tabular}

Table 1b. Occupation-wise and Gender-wise distribution of sampled population.

Gender-wise and occupation-wise distribution of the sampled population is given in the Table $1 \mathrm{~b}$. The distribution revealed that 68.6 percent were male and 31.4 percent were female respondents. According to occupation 23.5 percent were engaged in agriculture, 16.5 percent in household work, 10.4 percent as labour (unskilled workers), 9.1 percent skilled workers and 12.2 percent in service (government and private together). Among the sampled population 3.0 percent were coolie and 1.2 percent were 'driver'.

\section{Discussion}

The analysis is divided into two parts. The first part gives a detailed comparative scenario of understanding and attitudes of male and female respondents. Understanding of prescribed tests for HIV/AIDS, attitude towards patient and disease, knowledge and participation about awareness programme/s, transmission of HIV/AIDS, and some general information about HIV/AIDS have been included in the analysis.

The second part contains mapping of comparative cultural distance graphs for male and female respondents in one area covered during the survey study i.e., transmission of HIV/AIDS. 
The authors, elsewhere, have suggested an empirical method of measuring cultural distance of set of population, from a given scientific phenomenon. The suggested empirical model uses number of years of schooling as the proxy-scale for measuring the cultural distance ${ }^{37}$. Using the cultural-distance model five scientific notions, related to modes through which HIV could be transmitted, were subjected to scrutiny. For each of these notions distance of point-of-democratisations from origin was computed.

\section{Sources of information on HIV/AIDS}

Television and radio are the most important sources of information about HIV/AIDS for both men and women (see table 2). When compared with men, women who receive information through the electronic medium scored marginally lower. It is important to note that more than 60 percent reported that they get information through television and 50 percent said that they get it through radio. India is considered a conservative society and discussions on such sensitive issues within family members are marked as taboo, therefore, it was revealing that one in four men and women respondents said that their sources of information about HIV/AIDS was discussion within family members. It clearly shows that when the stakes are high and impact of a scientific phenomenon on life is intense the information transcends social and cultural boundaries.

Analysis revealed that newspapers are able to reach HIV/AIDS related information to one in three men and one in four women, which commensurate with the national spread of the newspapers in the country ${ }^{38}$. One in five respondents reported that they received information through Primary Health Centres (PHCs) and hospitals.

The response percentages mapping also shows that NGOs and social workers play a peripheral role in determining the information flow. Contrary to the belief that 'NGOs in India, have been making significant contributions in the HIV/AIDS prevention programmes, ${ }^{39}$ the analysis shows that put together, all of them are able to touch less than 11 percent of the total population. ${ }^{40}$ Since the issues are considered culturally sensitive, a substantial portion of funds allocated to HIV/ AIDS campaign are rooted through the NGOs.

\section{Test for HIV/AIDS}

'What action should be taken to check if someone has acquired HIV infection?' was the query put to each respondent (see table 3). It was a multiple-choice question and respondent was allowed to choose more than one answer. In response to this question more than 70 percent of sampled population said that blood should be tested for HIV/AIDS and more than 66.1 percent of all the respondents said that doctor should be consulted. It could be concluded that HIV/AIDS campaign in India is successful in conveying to the common citizen that 'when in doubt get the blood examined' or 'immediately consult a professional doctor'. It should be clarified here that, in India, the word 'doctor' is used for both a 'general physician' and experts'. This also indicates a distinction between traditional and modern system of medicine.

It is important to note that blood test cannot be conducted without consulting a doctor yet a lesser percentage of respondents ticked 'consult a doctor' as an option. The reason is understandable, 'blood examination is the only method that would confirm or reject the possibility of HIV infection' is imbibed in their cognitive structure, therefore, respondents did not consider it necessary to reiterate that doctor should be consulted, it was implicit in their response. For this set of respondents consulting a doctor who will not recommend a blood test, was not sufficient.

The percentage of respondents who believed that a person infected with HIV must consult a 'local quack' was quite low i.e., 6.7 percent among men and 7.3 percent among women. These respondents were mainly those who had no or low education (up to primary level) and engaged in labour work, pettytrading and as drivers.

\section{Transmission of HIV/AIDS}

The next question posed to the respondents was 'how HIV/AIDS spreads from person to person?' Openended question was administered to probe the perception of the respondents about possible modes of 
transmission of HIV/AIDS. Various responses obtained and the percentage for each is given in the Table 4. This question was also a multiple-choice query. Each response was considered as a separate unit of analysis and the average was calculated by adding all responses. The average percentage computed for this area for male respondents was 37.60. The total obtained formed the base and was used as divider for all answers considered as 'true'. Response 'transmission through sexual contact' scored the highest (70.5 percent) among male respondents. Similarly, highest percentage (64.8 percent) among female believed that HIV/AIDS spreads 'through sexual contact' but they scored about six percent less than the male respondents. The average percentage of correct answers rendered by women respondents was 34.69.

The possible modes of HIV infection in Indian population is 85.3 percent by sexual transmission, 2.7 percent each by mother to child and blood transfusion, 2.4 percent by needle sharing (IDU) and 6.9 percent by some unknown reasons ${ }^{41}$.

Besides the responses, those were categorized as scientifically correct, substantial segment of respondents also believed in scientifically invalid modes of transmission of HIV. These were mosquitobite, sharing food and clothes with the infected person, by hugging a patient, transmission through saliva and sweat (see table 5). The populace did not invoke supernatural powers and therefore, no response was categorized as 'extra-scientific'. The average incorrect response computed for men was 28.62 and for women it was 27.97 . It is noteworthy that the difference was less than one percent. It could be concluded that the scientifically wrong information has spread among men and women to almost an equal extent whereas the scientifically valid reasons for the spread of HIV are more prevalent among men compared to women.

When compared with women, more men believed that a person infected with HIV could lead a normal life. Similarly, a higher percentage of men believed that a patient of HIV infection should immediately consult a doctor in a proper hospital. Curiously, compared to men a larger number of women believed that 'AIDS cannot be cured'. The percentages of male and female respondents who said that an infected person should consult a social worker were quite low (10.6 percent male and 11.1 percent female) (see table 6).

\section{How can HIV/AIDS infections be prevented?}

World Health Organisation (WHO) along with National AIDS Control Organisation (NACO) ${ }^{42}$, India, have prescribed definite measures, which ensure prevention of infections from an HIV infected person to others. These instructions were included in the questionnaire to solicit opinion of Indian public. Each individual was asked to select a set of measures that in her/his opinion could impede the spread of HIV infection. The statistical analysis quite clearly showed that 'Abstinence', 'Having one uninfected sex partner' and 'safer sexual' practices are now an integral part of the cultural thought complex of more than fifty percent of the Indian population (see table 7). Women scored comparatively low percentage; almost fifty percent of the women also knew the method of preventing spread of the virus. Men and women both scored low when they were asked if the 'syringe sharing' or 'blood transfusion' could be potential source of infection. The reason can be attributed to the control they exercise in situations when injection is to be administered to a patient or in case of blood transfusion. In Indian conditions, an ordinary citizen is not empowered to intervene or exercise any influence on health practitioners. The authors have repeatedly argued that propagation of scientific information and tenets are quite closely linked to a citizen's ability to exercise control over the scientific phenomena. When the possibility of intervention and control is low the absorption of the scientific information is also low.

Analysis showed that 56.2 percent men and 53.3 percent women are aware that abstinence from unsafe sex prevents spread of HIV infection. Among men 57.6 percent and among women 53.7 expressed that having 'one uninfected sex partner' keeps the virus away. 53.3 percent men and 48.7 women said that 'safe sex' or using condom prevents spread of the infection. 38.6 men and 35.7 women respondent knew that in order to prevent HIV infection only 'non-reusable syringes' should be used. About one in three men (28.7 percent) and one in four women (26.5 percent) said that HIV could spread though unsafe blood transfusion. About one in ten men (11.6 percent) and equal percentage of women (11.6 percent) said that 'shaving razor should not be shared', as such a practice could be a potential source of HIV infection. 


\section{Cultural distance}

Let us reiterate that the cultural-distance here is defined as the distance travelled by a (scientific) phenomenon, on socialization scale (socialization through formal education), to cross the point of democratisation and become part of public culture. The point of democratisation for a dichotomous variable is where 'scientifically valid' and 'scientifically invalid' response curves intersect. It is the point beyond which more than 50 percent the sampled population believes in scientifically valid explanation.

The responses to questions on transmission of HIV/AIDS were subjected to scrutiny. The cultural distance of each of the five issues from the thought structure of two population segments, i.e. first constituted by men and the other by women, were computed separately. The authors, in this article, have included all the graphs that were constructed through quadratic curve estimation; however, Figure 6 and 7 give the magnitude of the comparative cultural distance of five selected notions associated with HIV transmission for men and women, respectively.

Analysis revealed that except for 'transmission of HIV/AIDS through breast feeding' when treated as a collective, the magnitude of cultural distance of the women respondents was found to be less than their male counterparts. For all other notions women were placed at farther distance when compared with men.

The value of cultural distance for 'transmission of HIV/AIDS through sexual contact', which is the most prevalent mode of transmission of the virus, was found to be negative (see figure $1 \mathrm{a} \& \mathrm{~b}$ ) or the point of democratisation is placed in the second quadrant. The value computed for male respondents was -1.0 year and for female respondents it was -0.5 years. Similarly, the cultural distance graphs were plotted for 'transmission through infected blood transfusion' (see figure 2 a \& b), 'transmission through sharing syringe/needle' (see figure 3 a \& b), 'transmission through breast feeding by infected mother' (see figure $4 \mathrm{a} \& \mathrm{~b}$ ) and 'transmission through razor sharing' (see figure $5 \mathrm{a} \& \mathrm{~b}$ ).

Transmission through sexual contact
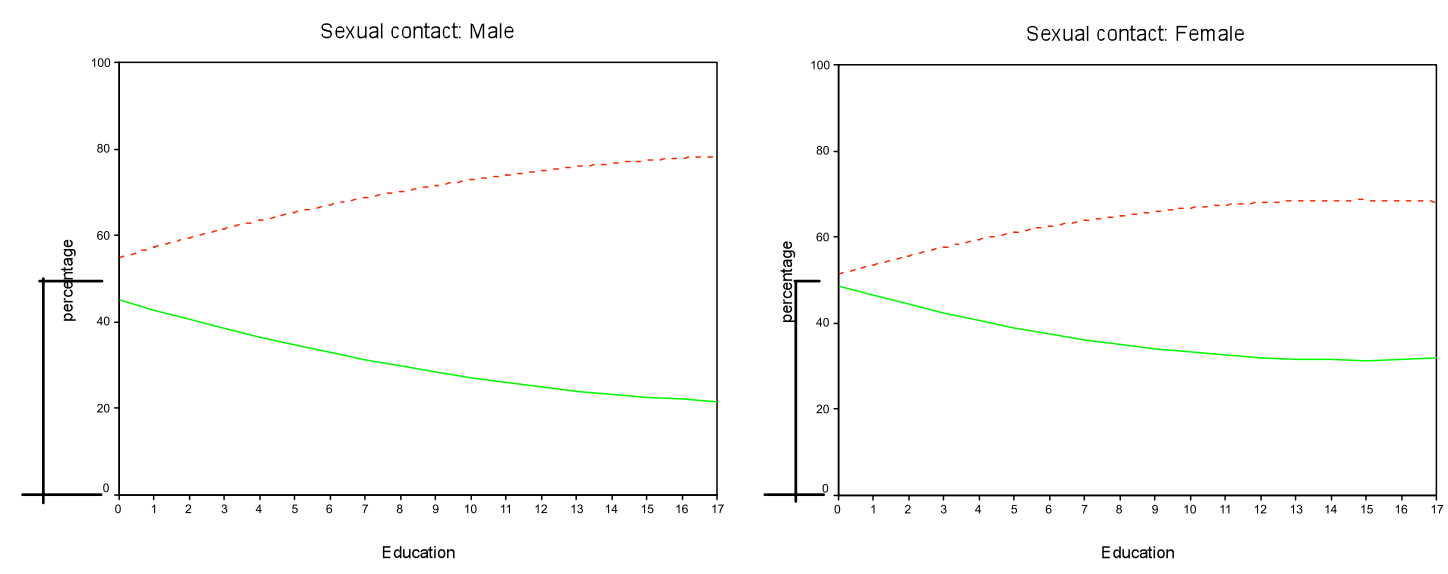

Figure 1 a \& b. Showing cultural distance for transmission of HIV/AIDS through sexual contact for male and female respondents. 
Transmission through infected blood transfusion
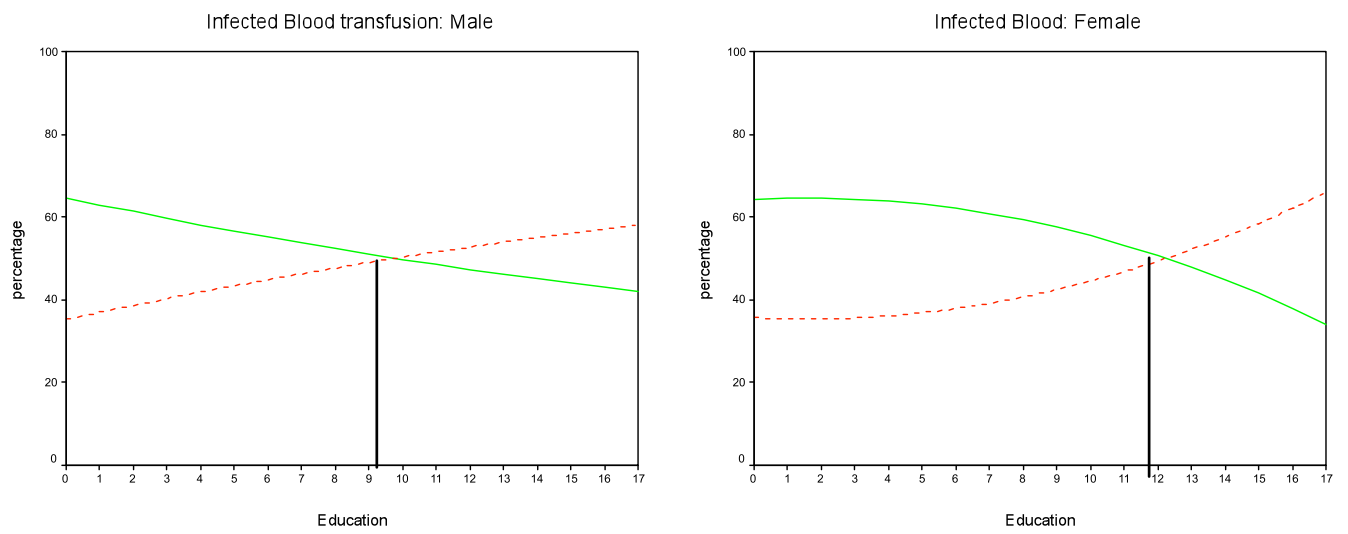

Figure 2 a \& b. Cultural distance for transmission of HIV/AIDS through infected blood transfusion for male and female respondents.

Transmission through sharing syringe/needle
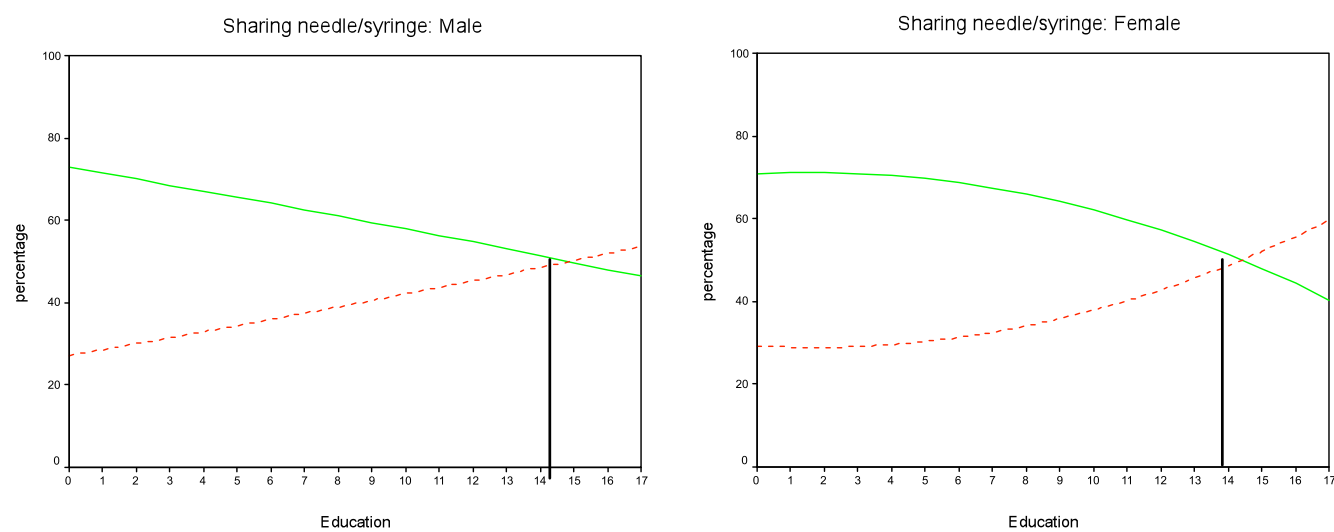

Figure 3 a \& b. Cultural distance for transmission of HIV/AIDS through sharing syringe/needle for male and female respondents.

Transmission through breast feeding by infected mother
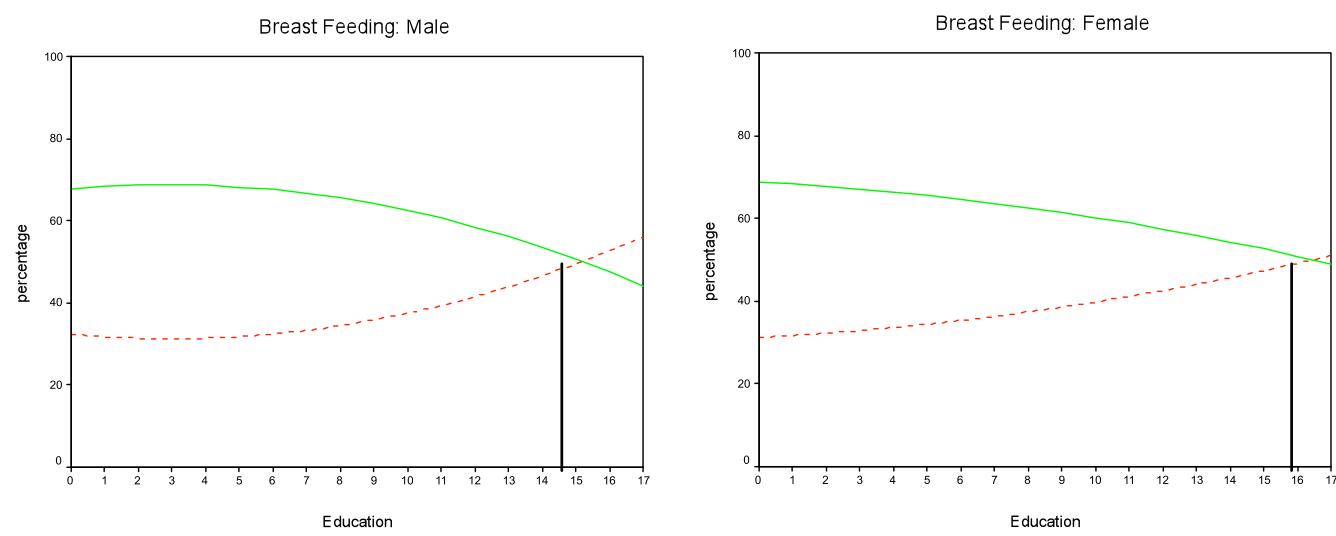

Figure 4 a \& b. Cultural distance for transmission of HIV/AIDS through breast feeding by infected mother for male and female respondents. 

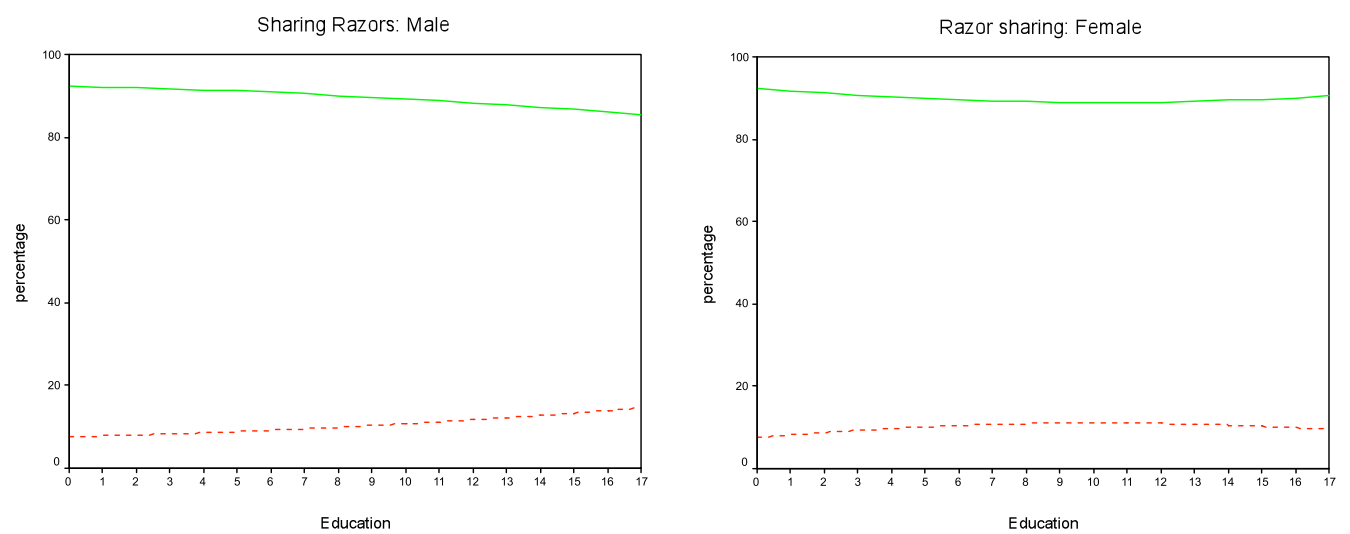

Figure 5 a \& b. Cultural distance for transmission of HIV/AIDS through razor sharing for male and female respondents.

\section{Conclusions}

Following conclusions are drawn on the basis of representative data set collected from 10 states of India. Male respondents scored higher than female counterpart with varied intensity. The social structure in India is such that females share more information among themselves and hence the information on HIV/AIDS is also discussed among womenfolk. Health rarely becomes the part of discussion among male members. Hence, female segment scored higher on 'family member' as source of information on AIDS.

Men were better informed about blood investigation as confirmatory test for HIV/AIDS diagnosis. The reason for low awareness among women could be attributed to low level of education, lesser exposure to the world outside four walls of the houses and thirdly to the cultural behaviours towards blood donation. In India, women rarely donate blood voluntarily. Men as a group are the major source of donated blood. Blood donation camps organized by government and voluntary organization and are major informationdissemination centres.

For transmission again male respondents' average is 3 percent higher than the female respondents. But for the question whether AIDS can be cured or not, female respondents were more informed than males. Their categorical response was 'AIDS cannot be cure'.

On the whole, women as a segment of Indian population could be placed at a farther cultural distance from the scientific explanations of modes through which HIV is transmitted, compared to men. Though the difference in cultural distances are not large it is important to note that in India agencies responsible for HIV/ AIDS will have to direct their effort to devise special modules for reaching out to women. They cannot be made active partners in HIV/AIDS campaign without reducing the comparative cultural distance.

\begin{tabular}{|l|c|c|}
\hline & \multicolumn{2}{|c|}{ Gender } \\
\hline Television & Male & Female \\
\hline Radio & 63.8 & 61.7 \\
\hline Family members & 54.3 & 49.2 \\
\hline Newspaper & $\mathbf{2 5 . 9}$ & $\mathbf{2 6 . 3}$ \\
\hline Hospital & 29.5 & 24.7 \\
\hline NGO & 22.5 & 21.3 \\
\hline Social worker & 11.2 & 10.6 \\
\hline Health volunteer & 8.7 & 8.0 \\
\hline Wall posters & $\mathbf{7 . 3}$ & $\mathbf{8 . 3}$ \\
\hline
\end{tabular}

Table 2. Sources of information about HIV/AIDS. 


\begin{tabular}{|l|c|c|}
\hline Question & $\begin{array}{c}\text { Male } \\
\text { Response\% }\end{array}$ & $\begin{array}{c}\text { Female } \\
\text { Response\% }\end{array}$ \\
\hline Blood Test & 73.8 & 70.6 \\
\hline Consult a Doctor & 67.2 & 63.0 \\
\hline Consult social worker & 32.5 & 30.2 \\
\hline Consult a quack & 6.7 & 7.3 \\
\hline
\end{tabular}

Values in percent

Table 3. Response pattern for 'what should be done on HIV infections?'.

\begin{tabular}{|c|c|c|}
\hline $\begin{array}{l}\text { Do you know about some awareness programmes on HIV/AIDS } \\
\qquad \text { Govt. Programmes } \\
\text { TV/Radio } \\
\text { NGO's work } \\
\text { No }\end{array}$ & $\begin{array}{l}20.2 \\
42.1 \\
25.6 \\
6.3\end{array}$ & $\begin{array}{c}21.1 \\
39.3 \\
23.9 \\
8.3\end{array}$ \\
\hline $\begin{array}{l}\text { Is AIDS like any other disease } \\
\qquad \text { Yes } \\
\text { Incurable }\end{array}$ & $\begin{array}{l}40.8 \\
\mathbf{1 6 . 0}\end{array}$ & $\begin{array}{l}37.3 \\
17.0\end{array}$ \\
\hline All HIV infected persons have AIDS? & 54.5 & 49.2 \\
\hline Can AIDS patient be cured? & 25.8 & 23.6 \\
\hline Young, healthy persons can not be infected with AIDS & 21.4 & 19.7 \\
\hline $\begin{array}{l}\text { HIV/AIDS can be spread more by: } \\
\qquad \begin{array}{l}\text { Sex workers } \\
\text { Truck drivers } \\
\text { Poor } \\
\text { Migrants }\end{array}\end{array}$ & $\begin{array}{l}76.5 \\
59.3 \\
34.1 \\
16.2\end{array}$ & $\begin{array}{l}73.8 \\
53.4 \\
32.9 \\
15.1\end{array}$ \\
\hline Is it easier to talk about HIV/AIDS with family members? & 43.8 & 38.1 \\
\hline $\begin{array}{r}\text { HIV/AIDS is a God's curse on society. } \\
\text { Agree } \\
\text { Disagree }\end{array}$ & $\begin{array}{l}25.7 \\
54.0\end{array}$ & $\begin{array}{l}24.1 \\
51.8\end{array}$ \\
\hline
\end{tabular}

Table 4. Comparative response behaviour of male and female on societal issues.

\begin{tabular}{|l|c|c|}
\hline & \multicolumn{2}{|c|}{ Gender } \\
\hline Modes of transmission & Male & Female \\
\hline Sexual contact & 70.5 & 64.8 \\
\hline Infected blood transfusion & 47.3 & 42.1 \\
\hline Sharing syringes & 38.2 & 33.6 \\
\hline Mother to child & 21.8 & 20.0 \\
\hline Sharing razors & 10.7 & 9.3 \\
\hline Breast feeding & 35.6 & 35.1 \\
\hline Average & $\mathbf{3 7 . 6 0}$ & $\mathbf{3 4 . 6 9}$ \\
\hline Other modes of transmission perceived by public & 43.4 \\
\hline Mosquito bite & 43.9 & 33.6 \\
\hline Shaking hands & 35.5 & 24.4 \\
\hline Sharing clothes & 25.0 & 15.8 \\
\hline Sharing food & 15.8 & $\mathbf{1 2 . 0}$ \\
\hline Hugging & $\mathbf{1 1 . 8}$ & 49.4 \\
\hline Saliva & 51.0 & 17.2 \\
\hline Sweat & 18.2 & $\mathbf{2 7 . 9 7}$ \\
\hline Average & $\mathbf{2 8 . 6 2}$ & Values in percent
\end{tabular}

Table 5. Possible modes of transmission of HIV 


\begin{tabular}{|c|c|c|}
\hline What should be done by an infected person? & Male & Female \\
Lead normal life & 30.5 & 26.8 \\
Can't be cured & $\mathbf{2 6 . 9}$ & $\mathbf{2 8 . 4}$ \\
Consult hospital & 25.5 & 27.3 \\
Social worker & 10.6 & 11.1 \\
\hline
\end{tabular}

Table 6. Response behaviour of male and female on 'what should be done by an HIV infected individual?'

\begin{tabular}{|l|c|c|}
\hline & \multicolumn{2}{|c|}{ Gender } \\
\hline Methods to prevent HIV/AIDS transmission & Male & Female \\
\hline Abstinence & 56.2 & 53.3 \\
\hline Having one uninfected sexual partner & 57.6 & 53.7 \\
\hline Having safer sex & 53.3 & 48.7 \\
\hline No syringe sharing & 38.6 & 35.7 \\
\hline Safe blood transfusion & 28.7 & 26.5 \\
\hline No razor sharing & 11.6 & 11.6 \\
\hline
\end{tabular}

Table 7. HIV infection can be prevented.

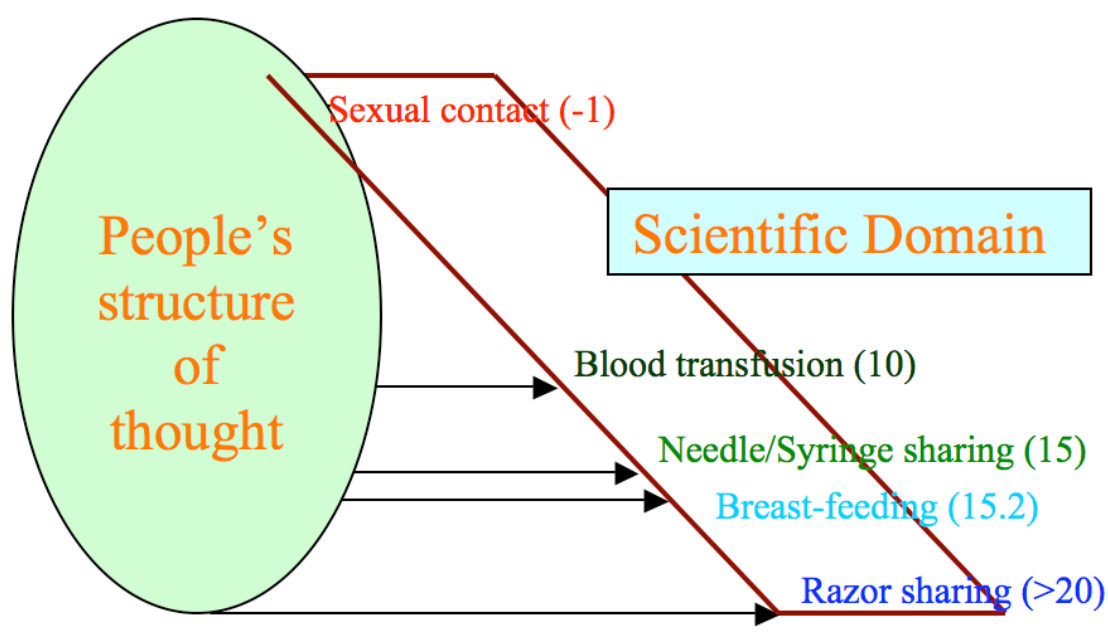

(value in number of years of schooling)

Figure 6. Diagrammatic representation of the relative cultural distance of various phenomena from cognitive structure of male respondents.

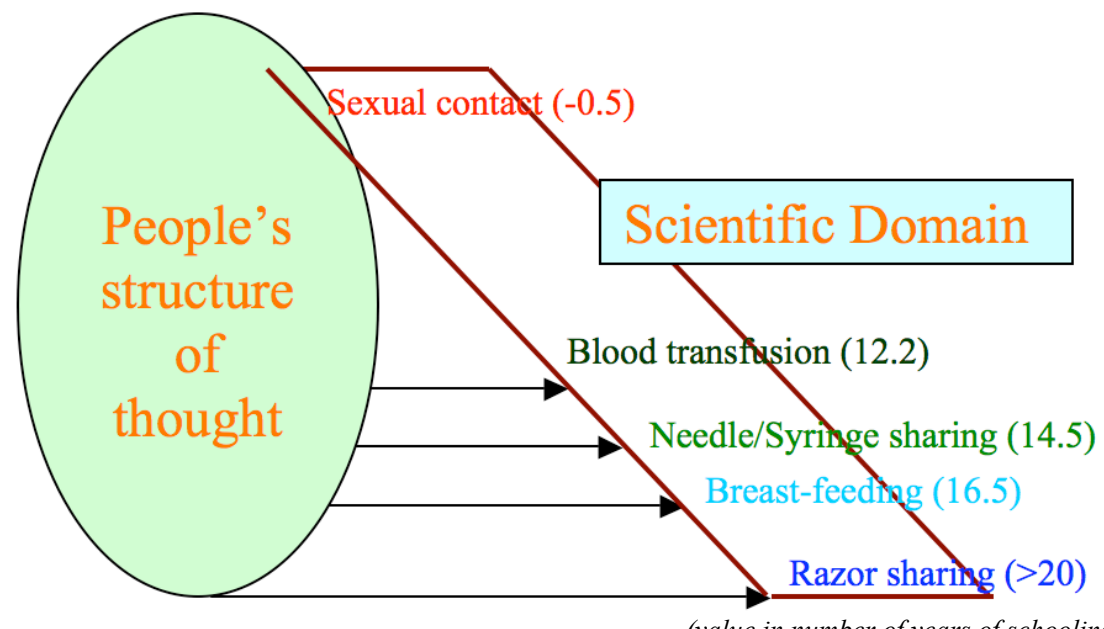

(value in number of years of schooling)

Figure 7. Diagrammatic representation of the relative cultural distance of various phenomena from cognitive structure of female respondents. 


\section{Notes and references}

${ }^{1}$ T. LaPorte and D. Metlay (1975), Public attitudes towards present and future technologies, Social Studies of Science 5: $373-398$.

${ }^{2}$ G.M. Pion and M.W. Lipsey (1981), Public attitudes towards science and technology: what the survey told us?, Public Opinion Quarterly 45: 303-316.

${ }^{3}$ R. Nabi Khan (1988), Science, scientist and society: public attitude towards science and technology, Impact of Science on Society 38: 257-271.

${ }^{4}$ National Science Board (1972-1998), Science and Engineering indicators US government printing Office.

${ }^{5}$ J. Durant, G. Evans and G.P. Thomas (1989), The Public Understanding of Science, Nature 340: 11-14.

${ }^{6}$ S.B. Withey (1959), Public opinion about science and the scientist, Public Opinion Quarterly 23: 382-388.

${ }^{7}$ J.D. Miller (1983), Scientific literacy: a conceptual and empirical review, Daedalus, 29-48

${ }^{8}$ G. Raza, B. Dutt and S. Singh (1989), Scientific Attitude among People, A Report on survey conducted during Kumbh Mela, Allahabad, NISTADS, (NISTADS-REP-107/91).

${ }^{9}$ E. Einsiedel (1991), Attitude towards science as consequence of scientific literacy among Canadian adults, paper presented at the $A A A S$, Washington.

${ }^{10}$ M. Bauer, J. Durant and G. Evans (1991), European public perception of science; an international comparative study, paper presented at the National Conference of the AAAS Washington.

11 R. Pardo and F. Calvo (2004), The Cognitive Dimension of Public Perceptions of Science: Methodological Issues, Public Understanding of Science 13(3): 203-227.

${ }^{12}$ W. Bodmer (1985), The Public Understanding of Science, The Royal Society, London.

${ }^{13}$ G. Raza, S. Singh and B. Dutt (2002), Public, Science and Cultural Distance, Science Communication 23(3): $293-309$.

${ }^{14}$ J.D. Miller (1991), Empirical comparison of public understanding of science in Japan and US, paper to the Annual Conference of the $A A A S$, Washington.

${ }^{15}$ Eurobarometer (1998), Evans and Durant, Understanding of science in Britain and the USA, National Science Board, Science and Engineering indicators.

${ }^{16}$ J. Ziman (1991), Public understanding of science, Science, Technology and Human Values 16: 99-105.

${ }^{17}$ F. Coyle and J. Fairweather (2005,) Space, time and nature: exploring the public reception of biotechnology in New Zealand, Public Understanding of Science 14(2): 143-161.

${ }^{18}$ L. Massarani and C. Moreira (2005), Attitudes towards genetics: a case study among Brazilian high school students, Public Understanding of Science 14: 201- 212.

19 J. Hagelin, H. Carlsson and J. Hau (2003), An overview of surveys on how people view animal experimentation: some factors that may influence the outcome, Public Understanding of Science 12(1): 67-81.

${ }^{20}$ D.J. Davidson and W.R. Freudenburg (1996), Gender and Environmental Risk Concerns: A Review and Analysis of Available Research, Environment and Behaviour 28(3): 302-339.

${ }^{21}$ M.F. Fox and G. Firebaugh (1992), Confidence in science; the gender gap, Social Science Quarterly 73: 101-113.

${ }^{22}$ F. Crettaz (2004), Gender difference in attitudes towards science in Switzerland, Public Understanding of Science 13: 191-199.

${ }^{23}$ M.L. Trankina (1993), Gender difference in attitudes towards science, Psychological Reports 73: 123-130.

${ }^{24}$ P.C. Stern, T. Dietz and L. Kalof (1993), Value orientation gender and environmental Concern, Environment and Behaviour 25: $322-348$.

${ }^{25}$ G. Raza, S. Singh and B. Dutt (June 2000), Public Understanding of Science in Complex Cultural Structures, JSIR 59: 460-470.

${ }^{26}$ C.H. Bernadette and N.T. Vicki (Oct 2001), Gender differences in scientific knowledge and attitudes toward science: a reply to a reply, Public Understanding of Science 10: 431-433.

${ }^{27}$ K.L. Dehne et.al. (May 1999), The HIV/AIDS epidemic in eastern Europe: recent patterns and trends and their implications for policy makers, AIDS 13(7): 741-749.

${ }_{28}$ AIDS vaccines research in Asia: needs and opportunities, Report from UNAIDS, WHO and NIID meeting Tokyo, October 1998 (30 July 1999), AIDS 13(11): 1-13.

29 A. Lansky, J.W. Ward and J.L. Jones (August 1998), Combination antiretroviral therapy for HIV infection: policies and practices, AIDS 12(12): 1552-1553.

${ }^{30}$ G. Raza, S. Singh and C. S. Pran (2007), HIV/AIDS; Public understanding and attitude, NYKS-JMI publication, Pullshoppe: India.

${ }^{31}$ S. Mehta and S. Sodhi (2004), Gender Perception: Micro Perspectives; A case study of Adolescent Girls in Chandigarh, India, 83-118, in Understanding AIDS; Myths Efforts and Achievements, APH Publishing House, New Delhi.

32 J.O. Neill (1990), AIDS as a Globalising Panic, in Theory, Culture and Society 7: 330.

${ }^{33}$ G. Raza, B. Dutt and S. Singh (1989), Scientific Attitude among People, A Report on survey conducted during Kumbh Mela, Allahabad, NISTADS, (NISTADS-REP-107/91)

${ }^{34}$ G. Raza, S. Singh and C.S. Pran (2007), HIV/AIDS; Public understanding and attitude, NYKS-JMI publication, Pullshoppe: India.

${ }^{35}$ Nehru Yuva Kendra Sangathan (NYKS) is an autonomous body under Ministry of Youth Affairs and Sports, Govt. of India. It currently has 500 district level offices, 2.16 lakhs village level youth clubs and 80 lakhs rural youth affiliated to it in 13-35 age group.

${ }^{36}$ G. Raza, S. Singh and B. Dutt (2002), Public, Science and Cultural Distance, Science Communication, 23(3): 293-309.

${ }^{37}$ Ibidem.

${ }^{38} \mathrm{http}: / /$ presscouncil.nic.in/Thestateof newspapersscene2007topci.pdf.

${ }^{39} \mathrm{http}: / /$ gateway.nlm.nih.gov/MeetingAbstracts/ma?f=102238224.html

${ }^{40}$ WHO report claims that 'NGOs receive a sizeable 13 percent of HIV funds, and their role as intermediaries could be still higher than this figure (S Sakthivel and S Nagpal, Tracking the flow of funds in the HIV/AIDS sector in India, WHO country office India, http://www.whoindia.org/en/Section2/Section232_1557.htm, seen on 13.01.2009). A WHO report mentions that 2000 NGOs and 100 corporate entities are 'dealing effectively' with TB/HIV (http://www.whoindia.org/en/section3/section123_1087.htm). However, 
a partial list of NGOs displayed by NACO shows that 104 Indian NGOs and 22 foreign organisations are specifically working on HIV/AIDS related issue. Detailed specific guidelines for grants, funding and working of these NGOs is available on http://dsacs.delhigovt.nic.in/naco pdf/guideline 5.pdf

${ }^{41}$ HIV/AIDS in India (2003), Population Foundation of India, Population Reference Bureau, New Delhi.

$42 \mathrm{http}$ ///www.nacoonline.org/NACO.

\section{Authors}

Surjit Singh has been working as Researcher at NISTADS (CSIR), India, in the area of public understanding of science and has been involved in large-scale survey studies for the last 20 years. He is also involved in science communication among school children and public understanding of HIV/AIDS related issues among public. E-mail: ssdabas@yahoo.com.

Gauhar Raza, working as a Senior Scientist at NISTADS (CSIR, India, is heading the unit Public attitude towards and understanding of science. He has organised more than survey studies in India and abroad on PUS. He was instrumental in suggesting 'cultural model' of public understanding of science. In addition, he is also involved in making films on scientific issues and writing poetry.

E-mail: gauhar_raza@yahoo.com.

S N Misra, a Botanist by training, is Head, Department of Bio-sciences, Maharishi Dayanand University, Rohtak. He has specialisation in stress physiological and handled many projects on the subject. He has many papers in his credit and has guided many students for their Ph.Ds.

E-mail: shyamnmishra@yahoo.com.

Pushpa Dahiya is working as Reader with Department of Bio-sciences, Maharishi Dayanand University, Rohtak. She has been working in the area of Fungal and Pollen Allergy.

E-mail: pushpa.dahiya@hotmail.com.

How to CITE: S. Singh, G. Raza, S.N. Misra and P. Dahiya, Mapping gender differences in understanding about HIV/AIDS, Jcom 08(03) (2009) A01. 